\title{
Communication
}

\section{Who is responsible for embodied $\mathrm{CO}_{2}$ ?}

\author{
Hans Sanderson ${ }^{1, *}$
}

1* Aarhus University, Department of Environmental Science, 4000 Roskilde, Denmark; sanderson@envs.au.dk Correspondence: sanderson@envs.au.dk

\begin{abstract}
With the Paris Agreement, countries are obliged to report greenhouse gas (GHG) emission reductions, which will ensure that the global temperature increase is maintained well below $2 \mathrm{C}$. The Parties will report their Nationally Determined Contributions in terms of plans and progress towards these targets during the postponed COP26 in Glasgow in November 2021. These commitments however do not take significant portions of the consumption related emissions related to countries imports in to account. Similarly, the majority of companies that report their emissions to CDP also do not account for their embodied value-chain related emissions. Municipalities, on the path towards carbon neutrality in accordance with the methods outlined by $\mathrm{C} 40$, also do not include imported and embodied $\mathrm{CO}_{2}$ in their total emission tallies. So, who is responsible for these emissions - the producer or the consumer? How can we ensure that the NDC's, municipalities and companies reduction targets share the responsibility of the emissions in the value-chain thus ensuring that targets and plans become, sustainable, climate fair, and just in global value chains? Today the responsibility lays with the producer, which is not sustainable. We have the outline for the tools needed to quantify and transparently share the responsibility between producers and consumers at corporate, municipal and national level based on an improved understanding of the attendant sources, causes, flows and risks og GHG emissions globally. Hybrid LCA/EEIO models can for example be further developed. This will, in the end, enable everyday consumption to support a more sustainable, green and low carbon transition of our economy.
\end{abstract}

Keywords: Sustainability; Climate; Trade; Models; Emissions; Value Chain; Justice

\section{Sustainability and un-goods}

The first United Nations (UN) global sustainability conference was held almost 50 years ago in Stockholm in 1972. The meeting report contains more than 100 recommendations on how to ensure global sustainability in the decades to come. Among these are a few critical pillars: 1 ) that sustainability is a global responsibility; 2) that sustainability is not only protection of the environment but also aimed at ensuring that future generations can live and prosper, and hence, that the economic model behind the exploitation of natural resources needs to be sustainable in the long term - not just short term; 3 ) that sustainability needs to be based on social justice between geographies, peoples, and generations; 4) that the full environmental embedded costs related to the production of goods are reflected in the price of a good - that the externalities are internalized in the price [1]. These recommendations still under-pin the global efforts. In the wake of Covid-19 the UN have formulated six recommendations for the recovery, among these that: a) Investments must accelerate the decarbonization of all aspects of our economy; $b$ ) Invest in sustainable solutions - fossil fuel subsidies must end and polluters must pay for their pollution; c) cooperation - no country can succeed alone [2].

The implications of sustainability and climate transition to a low carbon economy challenges our global economic models and cooperation [3]. In 1992, the German scientist Ulrich Beck published his seminal book, Risk Society, towards a new modernity. He argues that one can view our society via an inverse welfare economic perspective where societal transaction and economy are shifting risks - or transferring a risk or undesired un-goods 
implicit in the transaction, between societal actors. The risk is the opposite of what a transaction normally focusses on i.e. the material bought and money received. However, today actors also increasingly trade something none of them wants - climate disrupting greenhouse gasses. Hence, in addition to optimizing welfare there is an ongoing transaction to minimize risks taking place [4]. In a low carbon economy and climate change context the risk is the externalities, the unpaid pollution by the producer, in other words, the Greenhouse Gas (GHG) emissions embodied in traded products and services. The question is therefore, how to sustainably accommodate the explicit transaction of GHG emissions in global trade and emission inventories to enable a transition to a low carbon economy? The objective of this communication is to draw attention to the sustainability challenge of ignoring responsibility for embedded GHG emissions by the consumer at corporate, municipal and national level and indicate possible ways forward. This short communication will briefly demonstrate the challenges for including embedded GHG emissions in inventorying emissions at national, municipal and corporate level by reviewing the current applied methods for reporting at these levels.

The next section briefly outlines the relationship between GHG inventorying and transition to a low carbon economy.

\section{GHG emissions and transition to a low carbon economy}

Countries have developed the reporting methods and models for their national emission inventories to the UNFCCC [5] during the COPs resulting the guidelines laid down in the technical annexes of the Kyoto Protocol Art. 5, 7, 8. With the second Commitment Period of the Kyoto Protocol expired in Dec. 2020, countries report under the Enhanced Transparency Framework of the Paris Agreement (Art. 13) now. The methods relate to direct and indirect anthropogenic emissions (e.g. energy use and incineration) and natural emissions (e.g. agriculture) of GHGs developed under Kyoto continue under Paris. There is however, no requirement to account or report non-territorial emissions - i.e. the emissions embodied in a country's imports in the Paris Agreement. The United Kingdom (UK) is one of very few countries who have assessed their embedded emissions. The figure below depicts the GHG emissions embedded in imported goods and services compared to UK produced ditto, revealing that the embedded, and unaccounted, GHG is comparable to the domestic total GHG emissions. There are no formal requirements or guidelines for this analysis and hence also higher inaccuracies and uncertainties [6].

Million tonnes $\mathrm{CO}_{2}$ equivalents

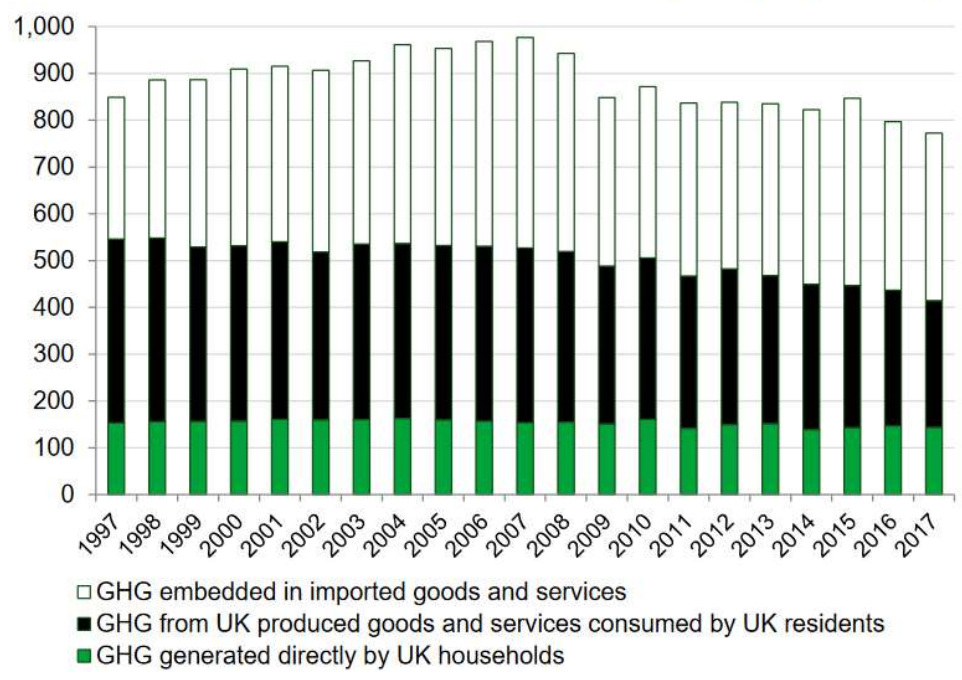

Figure 1. UK GHG emissions related to consumption 1997-2017 [6]. 
Municipalities, are increasingly also assessing and communicating their GHG emissions, carbon footprint and $\mathrm{CO}_{2}$ neutrality. There are no formal guidelines for these analyses at a municipal level; hence, the C40 cooperation [7] is widely viewed as the 'Gold Standard' for cities and municipalities. Embedded GHG (Scope 3) in products and services imported into a city or municipality are not included in the C40 inventorying methodology [8]. Since, C40 essentially follow a downscaled and simplified methodology of the national inventory described above, it can be assumed that the distribution between assessed and non-assessed emissions are on par with that of the UK - that roughly $50 \%$ of total emissions are not accounted for or reported.

Companies are reporting their GHG emissions to CDP [9]. In 2020, a total of 9526 companies representing more than $50 \%$ of the global market capitalization reported their GHG emissions. The companies assess their emissions based on the World Resources Institute (WRI) guidelines in the Greenhouse gas protocol [10]. Scope 3 (value-chain related emissions) is more complex and challenging than scopes $1 \& 2$ (direct and indirect emissions). Scope 3 reporting is more limited and less mature with only $78 \%$ of companies reporting at least one of the 15 Scope 3 categories required and only $23 \%$ engaging their value-chain in obtaining reduction targets, compared to Scope $1 \& 2$ reporting. Emissions located in Scope 3 are however, on average approximately four times higher than those from direct operations for a reporting company [11]. Considerable GHG emissions thus remain unaccounted for at corporate level.

The next section addresses how reporting could be made more sustainable in the original meaning of the concept cited under section 1.

\section{Sustainable reporting}

Transparency in the market is essential to maintain financial stability. It is therefore important that companies, municipalities and countries accurately and sustainably assess and disclose their full GHG emissions to enable investors to risk manage their investments. Disclosure will allow externalities to be incorporated in the price of goods and services and thus meet a prerequisite identified decades ago in Stockholm at the first UN global sustainability conference [1]. The devil is in the detail in these analyses, and we have to realize that we will all need to learn new analysis methods and data in the market place in order for the market to facilitate the transition to a low carbon economy and thereby address the global challenge of raising GHG emissions. The Science Based Target Initiative [12] is an example of how companies can comply with the Paris Agreement targets and require incorporation of Scope 3 emissions. Similar frameworks could be developed for municipalities mandating inclusion of Scope 3 emissions.

Dawkins et al. (2019), demonstrate at national level how environmentally extended multi-regional input-output models (MRIO) can be used to determine countries consumption-based emissions [13]. A decade ago, Peters (2010) showed trade-offs between applying different methodological approaches pertaining to the assessment of embodied GHG from input-output models to Life Cycle Analysis (LCA) depending on the type of organization being assessed. Where environmentally extended input-output models (EEIO) are relevant at large national scales and LCA are more relevant at company scales [14]. The most important deficiency of MRIO and EEIO, is that the emission data in the models are quite aggregate, typically nationally or regionally (e.g. European), as well as sectoral, and that the data are rarely updated, typically years between updates. EEIOs translate economic data into GHG emissions, which is good for simplicity but lacks the granularity that will enable informed choices for consumer between suppliers to get the least GHG 
emissions for the same good, which impairs differentiation and thus innovation. The solution to this could be an LCA approach. LCAs on the other hand, can become extremely detailed and complicated which impairs their usability. What needs to be included in the LCA and to what level of detail? Therefore, a compromise hybrid model could be considered that combines the ease of the EEIO with the specificity of LCA to allow informed, rapid and transparent GHG assessment of products so that producers can differentiate themselves on the market on this parameter [14]. Merging these two methods adopts the limitations and benefits of both. Refinement of hybrid EIO-LCA methods are exemplified on product and process level in the literature, and upscaling of this method to fit the needs of larger application is being investigated [15].

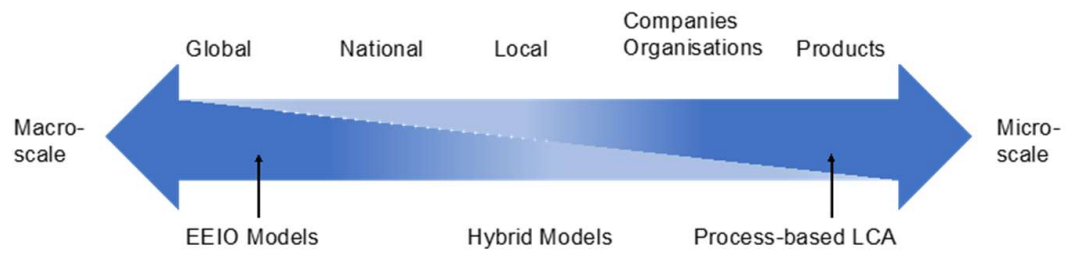

Figure 2: GHG assessment model types [14].

\section{Conclusions}

The answer to the overall question of who has the responsibility for embedded GHG emissions today is that it lays with the producer. Hence, more industrially advanced companies, municipalities and countries can outsource parts of their GHG emissions to suppliers. We need to reconcile if this in accordance with our perception of justice and sustainability - and if it is not, as suggested above, then apply methods to share the risk and responsibility between producer and consumer. We can do this by adapting and updating existing systems thinking of interconnected and interdependent systems concerning global trade and warming.. There is a public demand for sustainable and just GHG accounting. Moreover, there is an emerging political will to increase mitigation ambitions among the largest economies in the world (EU new climate law; China carbon neutrality in 2060, and the Biden administration new climate initiatives in the US). It is therefore important for the COP26 to consider sustainable accounting of value chain and non-territorial GHG globally. To further the development of analytical methods to account and disclose these transparently to ensure a transition to a low carbon economy and reaching Paris Agreement targets. Transitional risk is a significant and urgent risk climate change represents to society - understanding how we can adapt to the needed aggressive mitigation is a fundamental societal challenge and market disruption. There is a need for science to contribute with sound and applicable risk assessment methods to support countries, municipalities and companies to transition their business models to a low carbon economy. The methods and actions need to reflect and consider geopolitical implications of the transition [16]. The EU is considering a new carbon tax on imports, with the aim that if differences in levels of ambition worldwide persist regarding decarbonization, as the EU increases its climate ambition, the EU Commission will propose a carbon border adjustment mechanism to reduce the risk of carbon leakage where needed. The tax will contribute to global decarbonization while ensuring that the competitiveness of EU industry is not jeopardized by carbon leakage [17]. Clarifying the embedded emissions and risk [4] will allow the externalities to be transparent and internalized in prices [1]. Ultimately, when these risks and costs are transparent, then everyday consumer will be able express their willingness to pay to reduce emissions and thereby support a sustainable transition to a low carbon economy while reaching the Paris Agreement targets.

Funding: This research received no external funding. 
Acknowledgments: Thomas Stridsland, Aarhus University, and Karin Darville, Gladsaxe Musikog Billedskole, for discussions leading up to this communication.

Conflicts of Interest: The author declares no conflict of interest.

\section{References}

1. UN 1972: AF Conf 48/14 Rev1. URL: http://undocs.org/en/A/CONF.48/14/Rev.1 (accessed on 28 December 2020).

2. UN 2020: SDG 13: URL: https://www.un.org/sustainabledevelopment/climate-change/ (accessed on 28 December 2020).

3. Sanderson, H., et al. 2019. How do climate risks affect corporations and how could they address these risks? SN Appl. Sci. 1, 1720. https://doi.org/10.1007/s42452-019-1725-4

4. Ulrich Beck, 1992, The Risk Society - towards a new modernity, SAGE, London UK.

5. UNFCCC, 2020: Paris Agreement URL: https://unfccc.int/process-and-meetings/the-paris-agreement/the-paris-agreement (accessed on 28 December 2020)

6. Department of Environment, Food and Rural Affairs, 2017. UKs carbon footprint 1997-2017. URL: https://www.gov.uk/government/statistics/uks-carbon-footprint (accessed on 28 December 2020).

7. C40 network: URL: https://www.c40.org/ (accessed on 28 December 2020).

8. C40 network, 2019: Defining carbon neutrality for cities and managing residual emissions. URL: https://c40-productionimages.s3.amazonaws.com/researches/images/76_Carbon_neutrality_guidance_for_cities_20190422.original.pdf?1555946416. (accessed on 28 December 2020).

9. CDP, 2020: URL: https://www.cdp.net/en (accessed on 28 December 2020).

10. GHG Protocol, 2020, URL: https://ghgprotocol.org/ (accessed on 28 December 2020).

11. CDP, 2018, Global Supply Chain report: URL: https://www.cdp.net/en/research/global-reports/global-supply-chain-report2018 (accessed on 28 December 2020).

12. Science Based Targets Initiative, 2020: URL: https://sciencebasedtargets.org/ (accessed on 28 December 2020).

13. Dawkins E., Moran D., Palm V., Wood R., Björk I. 2019. The Swedish footprint: A multi-model comparison. Jour. Cleaner Prod. Vol. 209., 1578-1592.

14. Peters G. 2010. Carbon footprints of embodied carbon at multiple scales. Current Opinion in Environ. Sustain., Vol 2, Iss. 4, 245-250.

15. Towa, E, Zeller, V, Merciai, S, Schmidt, J, Achten, WM. Toward the development of subnational hybrid input-output tables in a multiregional framework. J Ind Ecol. 2020; 1- 19. https://doi-org.ez.statsbiblioteket.dk:12048/10.1111/jiec.13085

16. Leonard, M., J.Pisani-Ferry, J. Shapiro, S. Tagliapietra and G. Wolff (2021) 'The geopolitics of the European Green Deal', Policy Contribution 04/2021, Bruegel.

17. EU, 2020. Carbon boarder adjustment mechanism. URL: EU, 2020. Carbon boarder adjustment mechanism. https://www.europarl.europa.eu/committees/da/carbon-border-adjustment-mechanism/product-details/20201009CDT04181 (accessed on 28 December 2020). 